\title{
EL ABUSO SEXUAL: UN PANORAMA GENERAL
}

\section{SEXUAL ABUSE: AN OVERVIEW}

1 Doctor en Derecho. Maestro en Derecho Civil y Comercial. Miembro Honorario de los Colegios de Abogados de Tacna, Cusco y la Selva Central. Orden al mérito Francisco de Paula Gonzales Vigil por el Colegio de Abogados de Tacna. Con ORCID: https://orcid.org/0000-0002-4735- 8566

2 Estudiante del VII ciclo de la Universidad Femenina del Sagrado Corazón, miembro del Circulo de Derecho Penal - CEDEP, Ganadora del primer puesto en el Concurso Nacional de Ponencias Estudiantes desarrollado por el Colegio de Abogados de Huaura. Con ORCID: https://orcid. org/0000-0002-3505-4485

3 Estudiante del $V$ ciclo de la Universidad Femenina del Sagrado Corazón, miembro del Circulo de Derecho Penal - CedeP. CON ORCID: HTTPS://ORCID.ORG/0000-0001-6064-9416

José Julio Goicochea Elías ${ }^{1}$ Gianela Valeria Sipión Castillo² Samanta Yauyo Llimpe ${ }^{3}$ 


\title{
EL ABUSO SEXUAL: UN PANORAMA GENERAL
}

\author{
SEXUAL ABUSE: AN OVERVIEW
}

\author{
José Julio Goicochea Elías \\ Gianela Valeria Sipión Castillo \\ Samanta Yauyo Llimpe
}

\section{RESUMEN:}

En nuestra sociedad, no se le da la relevancia adecuada a lo que debería ser una preocupación palpitante y que cada día que pasa va en crecimiento. Nos referimos al abuso sexual siendo este entendido como aquella situación en la cual se vulnera a la persona y específicamente su intimidad, haciéndola sensible en todos los aspectos posibles. Este escenario es realmente lamentable para aquellas personas que lo sufren. No es nada nuevo encontrar, una vez más, a las mujeres inmersas en estadísticas que grafican la cantidad de abusos en contra de las mismas. Cabe resaltar que los menores son uno de los grupos vulnerables que tienden a estar vinculados a este tipo de acción que recae en una tipificación delictiva grave.

\section{PALABRAS CLAVE:}

Abuso, abuso sexual, intimidad, delito, mujeres, menores de edad, niños, matrimonio en menores de edad, Movimiento Activista Pedófilo, Caso Jeffrey Epstein.

\begin{abstract}
:
In our society, adequate relevance is not taken for what should be a palpitating concern that grows every day. We refer to sexual abuse being understood as that situation in which the person and specifically their privacy are violated, making them sensitive in all possible aspects. This scenario is really unfortunate for those who live it. It is nothing new to find, once again, women inmersed in statistics that explain the amount of abuse against them. It should be noted that minors are one of the vulnerable groups that tend to be linked to this type of action that falls into a serious criminal offense.
\end{abstract}

\section{KEY WORDS:}

Abuse, Sexual Abuse, Intimacy, Crime, Women, Minors, Children, Underage Marriage, Pedophile Activist Mivement, Jeffrey Epstein Case.

\section{INTRODUCCIÓN}

El presente artículo tiene por objetivo detallar el delito de abuso sexual, mostrando las diversas variantes que recaen en el mismo y, sobre todo, la esencia de su evolución ya que al cambiar la sociedad también trae consigo acciones que se convierten en un delito. Es preciso abordar todo lo que respecta a este tipo penal, tocando los polémicos casos de movimientos activistas que pretenden sustentarse en su libertad de expresión y preferencia sexual, para justificar el más aberrante delito que puede constituirse perjudicando directamente a menores de edad. Somos conscientes que estas personas son el interés superior del Estado.

Asimismo, revisaremos las tendencias actuales que pretenden normalizar las relaciones de los adultos con menores. Nos referimos por supuesto al matrimonio infantil o también llamado, matrimonio forzoso. Las estadísticas en el Perú demuestran fehacientemente que más de 56.000 de adolescentes con edad entre 12 a 17 años se encuentran unidas(os) en esa relación, representando al $1.9 \%$ de la población.

Plantearemos el caso polémico de Jeffrey Epstein, que resulta ser uno de los casos más trascendentes de los últimos años que involucró el trabajo de gente muy preparada como: la 
Policía de Estados Unidos el FBI , Fiscales, reconocidos abogados, y demás participantes para demostrar los delitos de Abuso Sexual, Pederastia, Prostitución, Tráfico de Menores, en todas sus modalidades, que había cometido Epstein durante años, en diferentes Estados y países formado una red de corrupción de funcionarios poderosos (élite) que le facilitaban el no ser acusado y seguir multiplicando exponencialmente sus víctimas.

\section{Estudio del Delito Abuso Sexual en el Código Penal Peruano}

\subsection{Actualizaciones}

Los constantes cambios en la configuración de los delitos en el Código Penal Peruano se deben generalmente a los cambios conductuales que se generan en la realización de los tipos conductuales de los integrantes del grupo social; con la evolución y la revolución de las industrias, tecnología, el modo de relacionarse de los ciudadanos muta, dando paso a nuevas construcciones sociales donde se van descartando determinadas conductas que antes probablemente eran aceptadas o irrelevantes. Ello va generando modificaciones en el desarrollo de los textos normativos y la traspolación de actitudes conductuales de un cuerpo normativo a otro: así tenemos que por ejemplo el adulterio que antes era delito, hoy en día es una causal de separación de cuerpos y divorcio ulterior.

Los cambios más significativos ocurren desde el reconocimiento de las mujeres como un género igual al de los varones, porque ciertamente a traves de la historia se ha comprobado que fueron un género muy discriminado al que ni se le reconocían los derechos básicos fundamentales. Situación que hoy en día si bien es cierto que ha disminuido, no ha podido ser erradicada por completo. Sería bueno que las nuevas generaciones conocieran que alguna vez en los Estados Unidos de Norte América existió una dama que respondía al nombre de Rosa Louise Mc Cauley Parks, (conocida como Rosa Parks) que en una época en que en la nación del Norte se vivía una segregación racial, -donde muchas veces un animal tenía un precio más alto en el mercado que una persona de raza negra-, el 1 de diciembre de 1955 se negó a cederle su asiento a un ciudadano de raza blanca y pasar a la parte trasera del autobus que la conducía a su domicilio.

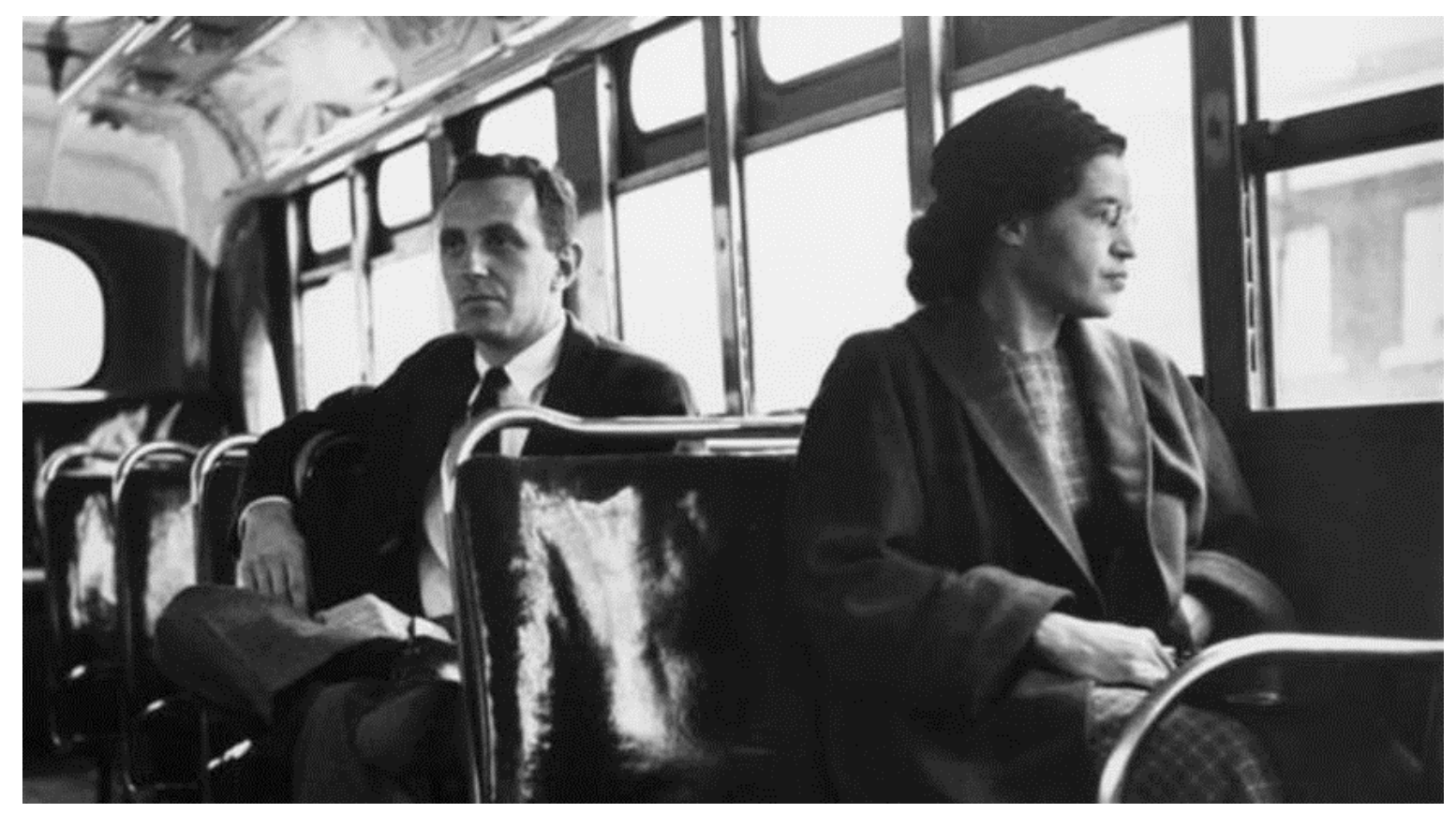


La llegada de corrientes revolucionarias, ha traído consigo una variedad de puntos de vista en lo que refiere a como medir a las personas; algo que debería ser normal, pero que sin embargo es objeto de estudio. Un ejemplo claro de ello, serían las feministas en todas sus variaciones, que pretenden hasta ahora reclamar derechos de igualdad y equidad para las mujeres, separados en grupos beligerantes, ya que algunas pierden la esencia de la equidad e igualdad y se subsumen en ideas con poco criterio y extremistas. Dentro de estás últimas se encuentran las feministas radicales que culpan a los varones de todas las desgracias que afectan a la humanidad. Si establecieramos una línea tiempo, notaríamos que dichmovimiento surge en la decada de los 60 "s del siglo próximo pasado, en un mundo que se encontraba en plena Guerra de Vietnam y de lucha por los derechos civiles, con conciertos musicales como Woodstock, proliferación de drogas alucinógenas y celebridades que luchaban por lo mismo pero apelando a metodos distintos. Nos referimos a Martin Luther King y a Malcolm X.

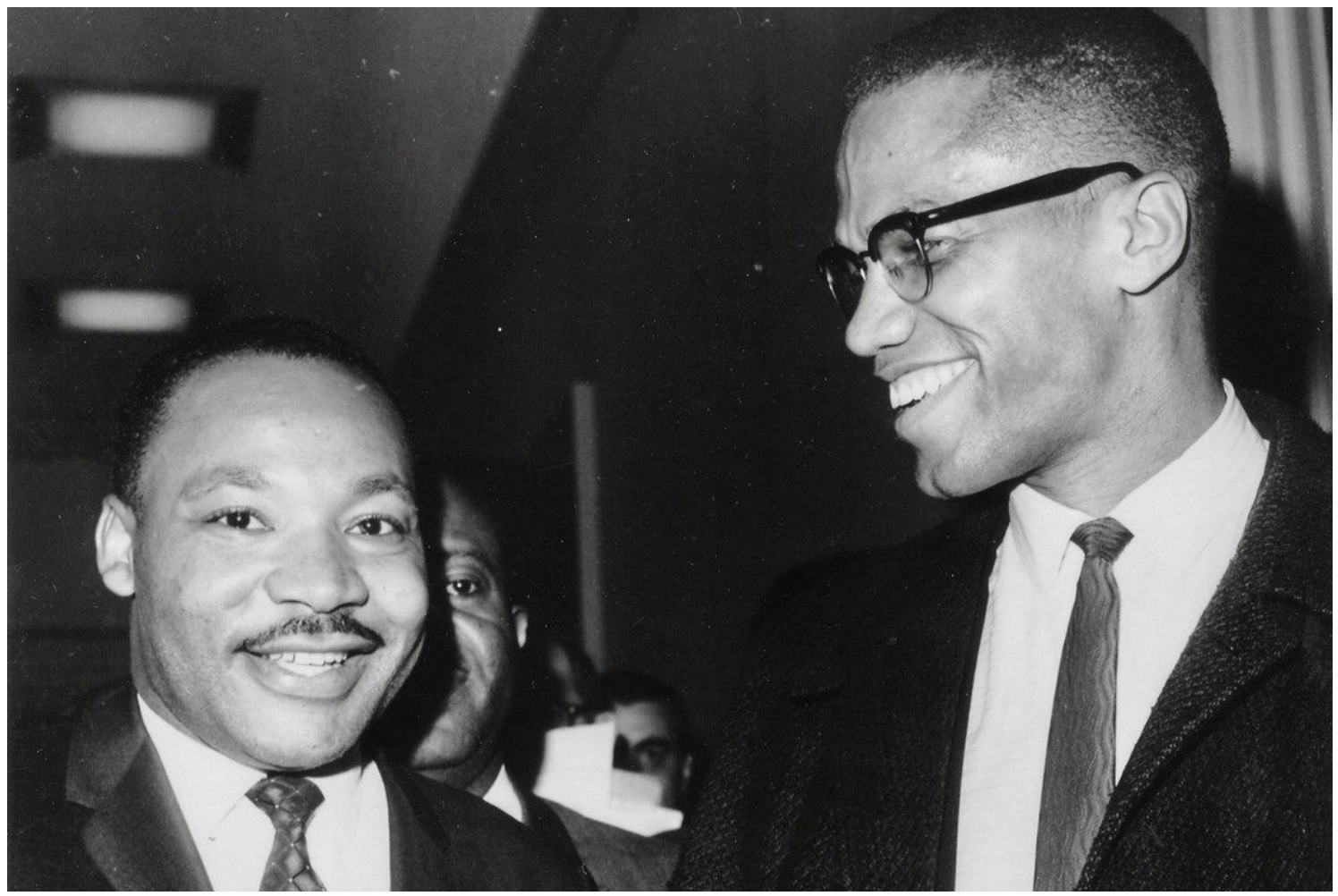

Ciertamente estos grupos radicales crearon un preámbulo para cuestionar la eficacia de nuestras normas en el tratamiento de los delitos y así con fuerza impulsan nuevos tipos penales que pueden y deben, en algunos casos, ser contemplados por el Derecho Positivo.

\subsection{La Teoría del delito}

En los delito de abuso de sexual se protege como bien jurídico a la integridad física, integridad psíquica, derecho a la libertad personal, el derecho a la intimidad, la moral de la víctima como también la tranquilidad y paz de las personas que pueden ser afectadas.

Si nos adentramos un poco y analizamos detenidamente dicha conducta delictiva, encontraremos a un sujeto activo que puede ser un hombre o una mujer sin distinción, el mismo que va a incurrir en actitudes como presionar u obligar a un sujeto pasivo en este caso víctima a realizar algún acto sexual que no quiera hacer controlando su actividad sexual sin su consentimiento. $O$ sea, nos encontramos ante un delito común, que no requiera ninguna condición especial en el agente que desarrolla el tipo delictual. 
Es un delito, que se comete con factores cognitivos y volitivos, ya que el agente o sujeto activo sabe muy bien lo que esta haciendo y tiene la voluntad de hacerlo por tal motivo es un delito plenamente doloso. Existe una conciencia de querer realizar la acción.

La pena por este delito va a depender de la conducta del victimario, así como la edad y condición de la víctima, donde se puede presentar de forma simple o agravada. Es en acciones como estas que se debe configurar la función de prevención general que cumple el Derecho Penal como elemento de control social. Ello por cuanto la prevención secundaria va a operar sobre el confinado y pertenece más a los terrenos que abarcan la Política Criminal y el Derecho Penitenciario. Si bien es cierto que el Derecho Penal es de última ratio, y que la cárcel es la excepción. En figuras como esta se debe de encontrarse responsabilidad, aplicar el peso máximo de la ley.

No obstante, nos gustaría citar a Nieva (2013) cuando precisa que

Por tanto, no es preferible absolver a cinco, diez, cien o mil culpables antes que condenar a un inocente. Y, desde luego, tampoco sería preferible condenar a mil inocentes, antes que absolver a un culpable, como demasiadas veces piensa la sociedad dependiendo de cuál sea el delito. No hay más que condenar a quien condenen las pruebas. Y absolver a quien las evidencias presenten como inocente (2013:167).

\section{Diferentes configuraciones}

Este delito, es tan extenso al momento de su realización que contempla diferentes supuestos y variantes, en cada una se va a diferenciar la acción, la consecuencia y la pena.

Es posible que en un futuro contemple nuevos supuestos o detalle mejor la realización de cada uno, todo esto obedeciendo al pedido de justicia de las víctimas. No debemos de perder de vista, que de todas las ciencias sociales, la jurídica es la más relativa. El Derecho no es un juego de probeta y muda conforme van evolucionando las conductas. Nos viene a la memoria los versos de una canción que interpreta Mercedes Sosa cuando señala que cambia lo superficial y también lo profundo.

\section{Y por casa como andamos?}

En el Código Penal Peruano, podemos diferenciar hasta seis tipos de abuso o violación sexual y cinco tipos de su variante como tocamientos, acoso sexual, etc. en donde no se consuma el acto.

\subsubsection{Detallaremos cada uno de estos a fin de precisar los diferentes tipos penales que abordan el tema que es materia de este trabajo de investigación}

\begin{tabular}{|c|c|}
\hline CONDUCTA & PENALIDAD \\
\hline DELITO DE VIOLACIÓN SEXUAL & \\
\hline $\begin{array}{l}\text { El que, con violencia ya sea física o psicológica bajo } \\
\text { amenazas o cualquier condición que inhabilite a la victima } \\
\text { de dar su consentimiento y por esto va a obligar a tener } \\
\text { acceso carnal; vaginal, anal, bucal y cualquier acto } \\
\text { análogo, valiéndose de algún objeto o partes de su cuerpo } \\
\text { por vía vaginal o anal. }\end{array}$ & $\begin{array}{l}\text { La pena pena privativa de la libertad } \\
\text { según el artículo } 170^{\circ} \text { será de catorce } \\
\text { años como mínimo a veinte años } \\
\text { como máximo. }\end{array}$ \\
\hline
\end{tabular}


El que, con violencia ya sea física o psicológica bajo amenazas o cualquier condición que inhabilite a la victima de dar su consentimiento y por esto va a obligar a tener acceso carnal; vaginal, anal, bucal y cualquier acto análogo, valiéndose de algún objeto o partes de su cuerpo por vía vaginal o anal.

Siendo el caso concreto:

1. Si se una un arma o más de 2 sujetos activos.

2. Si el sujeto activo abusa de su profesión, cargo legal que lo responsabiliza del cuidado del sujeto pasivo.

3. Si te trata de uno de los padres ya sean naturales o adoptantes, si reside en la misma vivienda o pueda ser pariente hasta el cuarto grado de consanguinidad, adopción o por afinidad hasta el segundo grado.

4. Si se trata de un sacerdote, pastor o cualquier líder religioso.

5. Si se trata de un profesor, auxiliar o cualquier cargo administrativo donde la victima recibe educación.

6. Si mantiene alguna relación laboral, si la víctima es una trabajadora del hogar.

7. Si se trata de un personal de la policía, fuerzas armadas, fuerza aérea, serenazgo, o cualquier funcionario público.

8. Si te trata de un sujeto activo que tiene conocimiento de una grave enfermedad de transmisión sexual.

9. Si te trata de un sujeto activo que tiene conocimiento de la presencia de un menor.

10. Si el sujeto pasivo es un embarazada.

11. Si el sujeto pasivo tiene entre catorce años y dieciocho años, es un adulto mayor o con alguna discapacidad ya sea física o sensorial.

12. $\mathrm{Si}$ el sujeto pasivo es mujer y coincide con cualquiera de los supuestos del artículo 108-B.

13. Si el sujeto activo se encuentra en estado etílico con un nivel de alcohol en la sangre mayor de 0.5 gr. o con drogas en su amplio espectro.

La pena será de veinte años como mínimo y un máximo de veintiséis años.

\begin{tabular}{|c|c|}
\hline CONDUCTA & PENALIDAD \\
\hline $\begin{array}{l}\text { DELITO DE VIOLACIÓN DE PERSONA EN ESTADO } \\
\text { DE INCONSCIENCIA O EN LA IMPOSIBILIDAD DE } \\
\text { RESISTIR } \\
\text { El que, inhabilite a la victima de dar su consentimiento } \\
\text { poniéndola inconsciente o cualquier posibilidad de } \\
\text { resistirse y por esto va a obligar a tener acceso carnal; } \\
\text { vaginal, anal, bucal y cualquier acto análogo, valiéndose } \\
\text { de algún objeto o partes de su cuerpo por vía vaginal o } \\
\text { anal. }\end{array}$ & $\begin{array}{l}\text { La pena según el artículo } 171^{\circ} \text { será } \\
\text { de veinte años como mínimo y un } \\
\text { máximo de veintiséis años. }\end{array}$ \\
\hline
\end{tabular}




\begin{tabular}{|l|l|}
\hline \multicolumn{1}{|c|}{ CONDUCTA } & PENALIDAD \\
\hline DELITO DE VIOLACIÓN DE PERSONA EN & \\
INCAPACIDAD DE DAR SU LIBRE CONSENTIMIENTO & \\
El que, inhabilite a la victima de dar su consentimiento, & $\begin{array}{l}\text { La pena según el artículo } 172^{\circ} \text { será de } \\
\text { veinte años como mínimo y un máximo } \\
\text { sabiendo que esta tiene o sufre alguna anomalía psíquica } \\
\text { por esto va a obligar a tener acceso carnal; vaginal, anal, } \\
\text { bucal y cualquier acto análogo, valiéndose de algún objeto } \\
\text { o partes de su cuerpo por vía vaginal o anal. }\end{array}$ \\
\hline
\end{tabular}

\begin{tabular}{|c|c|}
\hline CONDUCTA & PENALIDAD \\
\hline DELITO DE VIOLACIÓN SEXUAL DE MENOR DE EDAD & \\
\hline $\begin{array}{l}\text { El que, inhabilite a la victima de dar su consentimiento, } \\
\text { sabiendo que esta es menor de catorce años, por esto } \\
\text { va a obligar a tener acceso carnal; vaginal, anal, bucal } \\
\text { y cualquier acto análogo, valiéndose de algún objeto o } \\
\text { partes de su cuerpo por vía vaginal o anal. }\end{array}$ & $\begin{array}{l}\text { La pena según el artículo } 173^{\circ} \text { será de } \\
\text { cadena perpetua. }\end{array}$ \\
\hline
\end{tabular}

\begin{tabular}{|c|c|}
\hline CONDUCTA & PENALIDAD \\
\hline $\begin{array}{l}\text { DELITO DE VIOLACIÓN SEXUAL DE MENOR DE EDAD } \\
\text { SEGUIDA DE MUERTE O LESIÓN GRAVE } \\
\text { El que, inhabilite a la victima de dar su consentimiento, } \\
\text { sabiendo que esta es menor de catorce años, por esto } \\
\text { va a obligar a tener acceso carnal; vaginal, anal, bucal y } \\
\text { cualquier acto análogo, valiéndose de algún objeto o partes } \\
\text { de su cuerpo por vía vaginal o anal y en consecuencia el } \\
\text { sujeto activo causa lesiones graves o la muerte del menor. }\end{array}$ & $\begin{array}{l}\text { La pena según el artículo } 173^{\circ} \text {-A será } \\
\text { de cadena perpetua. }\end{array}$ \\
\hline
\end{tabular}

\begin{tabular}{|c|c|}
\hline CONDUCTA & PENALIDAD \\
\hline $\begin{array}{l}\text { DELITO DE VIOLACIÓN BAJO AUTORIDAD O } \\
\text { VIGILANCIA } \\
\text { El que, inhabilite a la victima de dar su consentimiento, } \\
\text { aprovechando la situación de dependencia del sujeto } \\
\text { pasivo, por esto va a obligar a tener acceso carnal; } \\
\text { vaginal, anal, bucal y cualquier acto análogo, valiéndose } \\
\text { de algún objeto o partes de su cuerpo por vía vaginal o } \\
\text { anal y en consecuencia el sujeto activo causa lesiones } \\
\text { graves o la muerte del menor. }\end{array}$ & $\begin{array}{l}\text { La pena según el artículo } 174^{\circ} \text { será } \\
\text { de veinte años como mínimo y un } \\
\text { máximo de veintiséis años. }\end{array}$ \\
\hline
\end{tabular}




\begin{tabular}{|l|l|}
\hline \multicolumn{1}{|c|}{ CONDUCTA } & \multicolumn{1}{|c|}{ PENALIDAD } \\
\hline DDELITO DE VIOLACIÓN SEXUAL MEDIANTE & \\
ENGAÑO & \\
$\begin{array}{l}\text { El que, mediante engaños inhabilita a un menor de } \\
\text { dieciocho años y mayor de catorce años, por esto va } \\
\text { a obligar a tener acceso carnal; vaginal, anal, bucal y } \\
\text { cualquier acto análogo, valiéndose de algún objeto o } \\
\text { partes de su cuerpo por vía vaginal o anal. }\end{array}$ & $\begin{array}{l}\text { La pena antículo } 175^{\circ} \text { será de } \\
\text { seis años como mínimo y un máximo }\end{array}$ \\
\hline
\end{tabular}

Los artículos que continúan en la norma penal sustantiva, se ocupan de delitos que son previos a la consumación de la violación sexual con penas entre dos años como mínimo y quince años como máximo, siendo aplicados con arreglo a la particularidad de cada caso.

Asimismo, en el artículo $177^{\circ}$ encontramos agravantes que se aplican a todos los artículos anteriores y pueden subir la pena en cinco años o en el peor de los casos llegar hasta la cadena perpetua.

\section{Tendencias no reconocidas de Abuso Sexual}

Junto con el desarrollo del colectivo social y las concepciones más equitativas de derechos con el fin de conseguir el libre desarrollo del plan de vida de cada ciudadano en pleno siglo $\mathrm{XXI}$, han venido surgiendo distintos grupos, inicialmente minorías que a viva voz claman por un reconocimiento y respeto en dirección a sus gustos o inclinaciones, como parte de su derecho al libre desarrollo de la personalidad, pero así como alabamos esta capacidad para mutar y buscar un calidad de vida en armonía con todos, debemos acusar a los grupos que se excusan en sus derechos para ocultar crímenes bárbaros.

\section{Matrimonio entre menores de edad}

El matrimonio forzoso es una de las maneras que tiene nuestra sociedad de demostrarnos que hay temas aún pendientes en el tintero. Puede entenderse como aquella unión entre menores de edad, pudiendo tener esta característica una de las partes o ambas. Claramente aquí no podíamos describir la manifestación de voluntad como algo propio ya que, así sea una o ambas partes las contrayentes, se pierde la esencia de tener una propia convicción para expresar su sentir de manera concreta sin ser persuadible por la edad.

Llegamos a este punto para demostrar que el matrimonio infantil puede traer consigo varios tipos de abuso, ya sean estos de índole físico, sexual, económico, personal, entre otros.

El tipo de abuso sexual, siendo este el tema materia de análisis, podría darse en el caso que, al estar una persona mayor casada con una menor de edad puede usar dichas características para someterla sexualmente. Por ejemplo, en un matrimonio forzoso, uno de los contrayentes (siendo el que tiene la mayoría de edad) podría usar los impedimentos presentes en la menor de no tener un acceso adecuado a los métodos de protección convencionales para evitar embarazos no deseados. Otro supuesto podría ser que el esposo al tener un control total sobre la cónyuge menor de edad puede llegar a abusar sexualmente de ella por el solo hecho de ser "su esposa". Esto lo mencionamos porque si en una pareja convencional, donde ambos expresaron en un determinado momento su voluntad para contraer matrimonio se da, sin estos tener ningún tipo 
de variable parecida a la del matrimonio infantil o forzoso, entonces ¿que podemos esperar en una pareja donde la menor es persuadible, inducible, y sobretodo está, en la mayoría de casos, superitada a lo que el esposo puede proporcionarle para el día a día?

Sabemos que los supuestos son extremos y, desde luego, no todos los matrimonios donde se encuentra inmerso un menor de edad se dan de esta manera. No obstante, las estadísticas nos muestran que día a día son mayores las situaciones negativas para aquellos menores que están en un matrimonio o mejor dicho, unión sin manifestación de voluntad expresa.

El abuso sexual tiene relación con el matrimonio infantil de alguna forma ya que una de las consecuencias de dicha unión sin manifestación de voluntad expresamente válida es que existe algún tipo de abuso, sobretodo sexual. Llegamos a esta idea porque cuando una persona mayor se casa con un o una menor, se dilucida según estadísticas la cantidad de exigencias que tiene este para con su "esponsal".

El Código Civil Peruano al parecer aprueba dicha situación que ha sido recientemente incorporada por el Decreto Legislativo 1384, ya que la norma antes mencionada inserta al artículo 42 la posibilidad matrimonial desde los 14 años. Si hablamos en términos civiles, podemos encontrar dicha figura como algo tradicional, ya que la unión en matrimonio es una de las bases más importantes de nuestra sociedad para conformar una familia. Consideramos que no hay motivo para exponer a menores de edad a situaciones en las cuales son visibles los roles desiguales, destruyendo sus proyectos de vida, su sentir personal, su libertad de identidad y sobretodo, dejar de lado el tan anhelado y buscado interés superior del niño.

En nuestro código penal, el artículo 173 nos hace visualizar el delito de violación sexual de menor de edad, colocando como sujeto pasivo al mismo, tipificando conductas tales como aprovecharse de su condición, amenazándolo (ya sea de manera física o psicógica) para que tenga acceso carnal con el sujeto activo que puede ser cualquier persona. Aquí nos detenemos. En el matrimonio infantil o forzoso, existen derivaciones y una de estas es la violencia, dado el caso, sexual.

En esta situación, la persona mayor puede valerse de dicha característica para violentar sexualmente a su pareja y sí, hablamos de violación dentro del matrimonio, mucho más si hay en el una situación de desigualdad por distintos factores.

Según lo recogido, pudimos encontrar distintos casos. Uno de ellos es de una adolescente de 14 años, proveniente de la ciudad de Cuzco. Esta contaba que una vez casada, con la pareja que tenía en ése entonces 55 años de edad, pudo notar el cambio y la realidad de como iba a desarrollarse la relación amorosa. En el noviazgo, propiciado por los padres de la menor por conveniencias de diferentes índoles, todo era maravilloso, sentía que era el hombre de su vida y realmente llegó a pensar lo mejor junto a él. Todo cambió una vez que se dieron el sí. La obligaba a mantener relaciones sexuales sin respetar lo que pudiera decir o sentir. Es más, si tratamos de encajar la figura legal de violencia sexual a menores de edad que yace en nuestro Código Penal, notaremos que absolutamente todos los verbos y acciones que traen consigo este delito se cumplen. Queremos dejar en claro que no se necesita un sujeto activo ajeno a la víctima, sino que unicamente basta con que la situación que se dilucida en el delito se cumpla, tal como lo hacen las consecuencias del matrimonio forzoso en menores de edad.

Si nos remontamos a Nepal, para dejar en claro que la realidad no solamente se da en el Perú, sino en todo el mundo, los padres preparan a sus hijas exclusivamente para ser unidas a edad temprana a cambio de cosas materiales que a la larga pudieran ser más 
útiles que sus propias descendientes. Estos progenitores expresan que cualquiera puede ofrecer ovejas, vacas, bienes, entre otras cosas que pueden ser materia intercambiable por sus menores hijas. Lo más increíble de todo lo antes leído es la facilidad con la cual estos entregan a desconocidos sus más preciados tesoros. Aseguran que mientras más joven se encuentren, menor será el esfuerzo para persuadirlas que ése es el futuro que les espera. No tienen mayor meta que casarse para que los padres puedan pagar sus deudas, cuando se supone que estos últimos son los que deben velar por el correcto desempeño de estas pequeñas.

Con todo lo antes mencionado queremos dejar en claro que existen distintas maneras de abusar de un o una menor, sobretodo si este está superitado a la pareja. Es una preocupación que el gobierno promueva tanta inequidad para con nuestros niños, niñas y adolescentes impidiéndoles desarrollarse plenamente, estancando sus planes a futuro.

\section{Pedofilia y Pederastia}

Es común confundir estos términos debido a que no solemos hablar de ellos, además, de lo delicado que puede ser abordarlos, ¿Por qué?, involucra como principal víctima a menores de edad, niños, que como lo precisamos previamente no tienen la facultar de dar un consentimiento para sostener relaciones sexuales.

La pedofilia y la pederastía comparten en su forma el ser parafilias, estas parafilias son definidas por la OMS (Organización Mundial de la Salud) como transtornos que tienen un carácter instenso y persistente de exitación sexual de manera atípica, estos pueden manifestarse en el fuero interno; mendinte fantasias y impulsos, y el fuero externo; mediante desórdenes sexuales.

En lo que respecta a la Pedofilia, se tiene que las princpales caráctristicas que presenta este transtorno es materializar sus fántasias, impulsos, comportamientos sexualemente excitantes

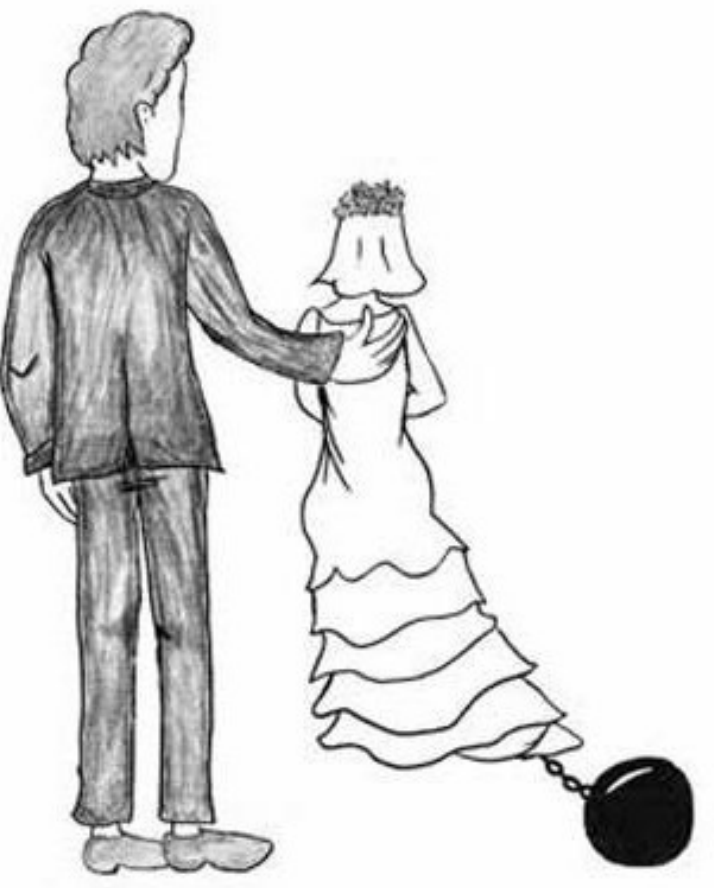
recurrentes y de gran intensidad, hacía menore de edad, a través de acercamiento ya sea con el uso de fotografías, videos, etc. pero no necesariemnete perpetrarán la violación sexual al menor.

Mientras que por el contrario, en la Pederastía, lo que se nos presenta es la atracción sexual de un adulto por un menor de edad, que va desembocar directamente en mantener relaciones sexuales. En conclusión esta parafafilia si términa siendo una conducta delictiva porque usa recursos como engaños y medios gravosos como violencia para perpetrar la violación sexual.

Si bien la pedofilia se caracterisa por mantener los impulosos en el fuero interno, o no materializar la violación al menor, no significa que no sea punible, es delito tener bajo posesión fotografías o videos de menores de edad sosteniendo relaciones sexuales y mucho más grave comercializar con ellos, pornografía infantil. 
Los estudios científicos suguieren que la zona de excitación localizada en el cerebro de los pedófilos o pederastas es diferente, pero esto no significa que pueda tomarse como excusa y declararlos inimputables, ya que no afecta su capacidad de decidir que hacer o detener ante los impulsos, es decir, son totalemente concientes de sus actos. Estos estudios concluyen que no existe posibilidad de identificar a un posible pederasta o pedófilo, cada persona a llega a esta situación con base a diversas experiencias, conflictos de la infancia o al haber crecido en entornos particulares, sin embargo, si existen algunas alertas que normalmente la policia a detectado en este tipo de agresores.

Se estima de que ocho de cada diez pederastas son hombres y dos son mujeres, en el caso de los hombres se promedia una edad de treinta a cincuenta años, lapso donde cometeran el delito en mayor proporción; y en el caso de las mujeres incide la misma edad pero tienen una preferencia de menores de cinco años y adolecentes en su mayoría.

Los pederastas y pedófilos presentan un perfil general con carateristicas comunes como: baja autoestima, poca tolerancia al estrés, sentimiento de inferioridad, difulcultad para relacionarse con la personas, tienen a la inamdures, no son empáticos, no sienten compación ante el sufriemiento del menor atacado. Aunque no sean reglas específicas de los pederastas o pedófilos, son señales que deberian alertarnos ante un posible agresor.

Es mucho más común que el agresor mantenga algún tipo de vínculo con la víctima, lo que propicia una especia de pacto que va a comprometer al abusador con el niño o niña evitando que la familia o autoridades se den cuenta del abuso.

Un pederasta o pedófilo normalmente se establece en un lugar donde pueda tener fácil acceso a niños o niñas; colegios, parques, ect. lo que le permite generar coartadas, estrategias que le permiten estar a solas con sus víctimas y establecer confianza.

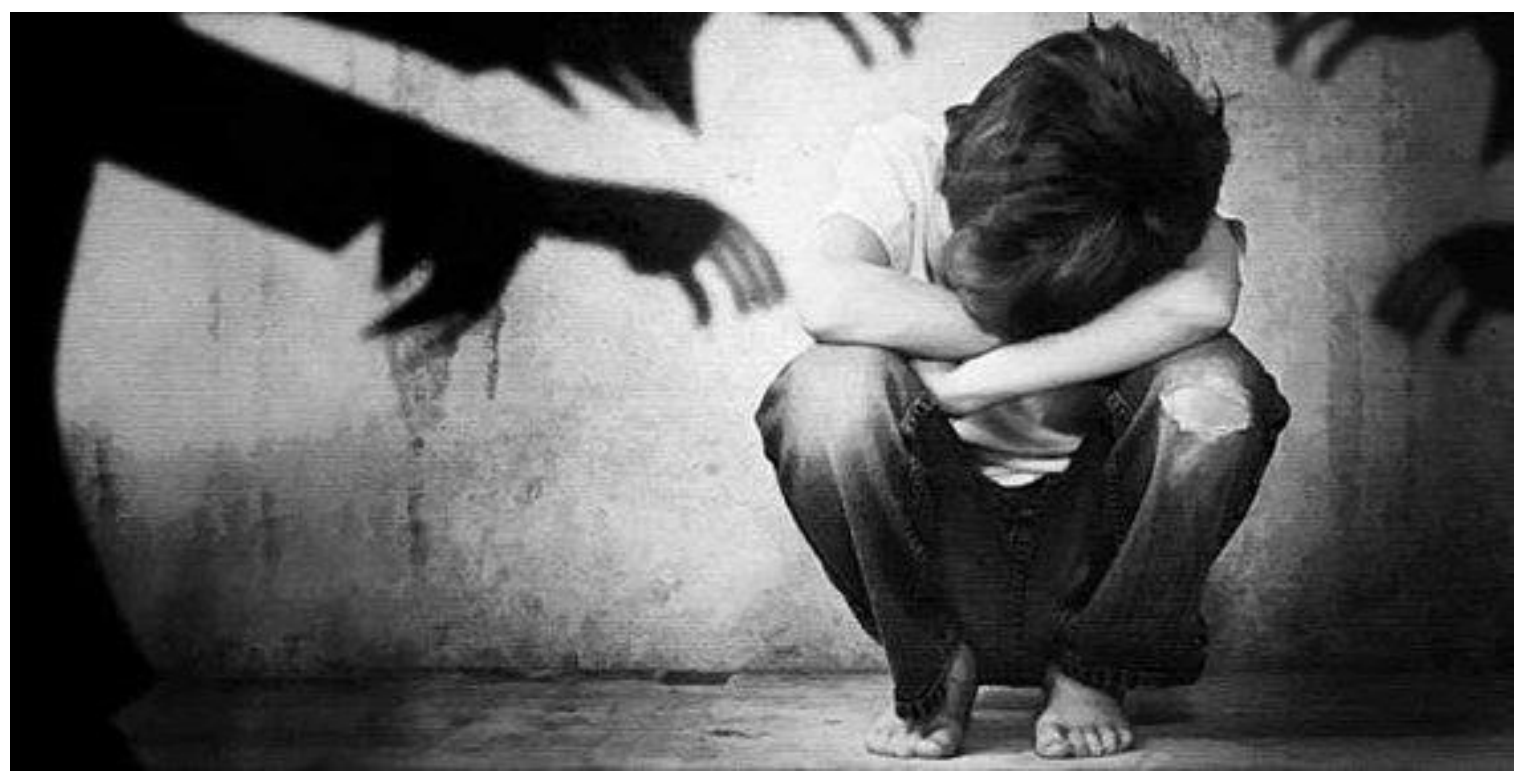

\section{El Movimiento Activista Pedófilo (MAP)}

El MAP es una organización de personas que se sienten atraídas por los niños. Es una agrupación de gente que está a favor de la pedofilia. Su bandera se compone de tres colores en distintas gamas: el color rosado para las niñas; En color celeste a los niños; El color blanco la pureza. Las personas que componen este colectivo creen en el amor hacia los menores de edad. 
Lo que ellos profesan es un amor en libertad sin restricción de edad. Es importante que nosotros entendamos la gran diferencia entre la comunidad LGBT+ y este grupo que tergiversa la lucha de derechos razonables. La comunidad LGBT+ se caracteriza por tener una gran variedad debido a sus diversas orientaciones sexuales e identidades de género entre sus integrantes. Este grupo se pronunció rechazando categóricamente al movimiento MAP tomando como argumentos que; la pedofilia no es una orientación sexual ya que es instituida por la OMS (Organismo Mundial de Salud) como parafilia o patología sexual. Además este movimiento pretende constituir, normalizar y naturalizar relaciones sexo afectivas entre adultos y niños adolescentes que no tienen la capacidad de consentir porque, desde luego, no tienen la madurez intelectual para hacerlo. Tomando estas razones como núcleo desconocen a MAP como un movimiento dentro de la comunidad LGTB+.

Es importante entrar en cuenta de la existencia de la pedofilia y el riesgo que corren nuestros niños y niñas.

\section{Jurisprudencia Internacional:}

Dentro del marco normativo creado a partir de copias imprecisas de leyes extranjeras notamos inconsistencias que poco a poco se van saneando en función a su aplicación y la variedad de supuesto que se van presentando en la cotidianidad. De ahí surge la gran importancia de prestarle atención a casos internacionales que van marcando pautas para el desarrollo y tratamiento de delitos difíciles de resolver.

\section{Њ}

\section{LA PEDOFILIA NO ES UNA ORIENTACIÓN SEXUAL}

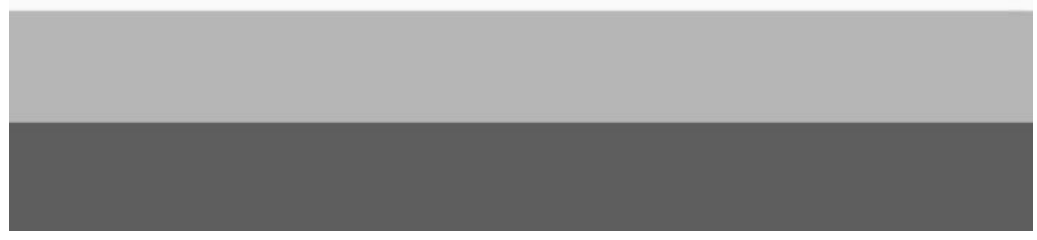

\section{El Caso Jeffrey Epstein}

Este caso trata de una serie de delitos contra menores de edad, tráfico y abuso sexual que inicia en Palm Beach Estados Unidos, sucede que se corre la voz entre los adolescentes por ir a la mansión "Rosa" y dar un masaje a un señor y por esto se ganaba 200 o 300 dólares, lo que no sabían era que no era sólo un masaje, el magnate Jeffrey Epstein aparecía desnudo con una toalla blanca y le pedía a las jóvenes de entre doce, trece, catorce años el masaje y luego que lo tocaran o veces él a ellas, según los relatos de las victimas o "sobrevivientes". Epstein cometía violaciones, 
manipulaciones, abuso sistemático sexual y psicológico. La idea era reclutar niñas fáciles de atraer, se trataba de mujeres pobres o de familias disfuncionales, es decir vulnerables.

Epstein tenía el perfil perfecto de la alta sociedad estadounidense: era un financiero exitoso además de un filántropo comprometido y muy inteligente así lo describa el propio Bill Clinton o el príncipe Andrew de Inglaterra, el hacía funcionar el dinero y con ello pudo hacer un círculo de conexiones que protegió su organización de pedofilia.

Gracias a su carrera de profesor de matemáticas y física pudo ingresar al Banco de inversión Spears y posteriormente asciende a socio ahí teje su red de contactos entre la gente muy influyente y adinerada en Estados Unidos hasta que 1982 lanzó su propia firma de inversiones donde asesoraba a los más ricos de entre los ricos. Obtuvo conexiones que aprovechó para traficar con las menores y sobornar a empresarios y políticos.

En el 2002 se hizo una denuncia en su contra, pero fue hasta el 2005 que se inició la investigación por la declaración de una sobreviviente de 14 años y 4 años después por fin fue acusado de actos sexuales ilegales contra una menor, pero gracias a las conexiones que tenía en 2007 llegó a un acuerdo con Alex Acosta quien entonces era fiscal federal en Florida. En lugar de enfrentar los cargos de tráfico sexual se declara culpable de solicitar prostitución y el juez dictaminó 13 meses de prisión. Esta prisión fue muy particular ya que le dieron una celda privada de la cárcel y permisos de salir a trabajar doce horas diarias seis días a la semana.

Una década después la bomba explotó con un artículo del Miami Health aquí resaltaban el trabajo del $\mathrm{FBI}$ que investigó minuciosamente dando como resultado el arresto de Epstein en el aeropuerto de Nueva Jersey el 6 de julio acusado de tráfico sexual de niñas menores, conspiración y cabecilla de una red de explotación y abuso sexual a menores desde sus propiedades en Manhattan y Florida entre dos mil dos y dos mil cinco su arresto no duró mucho ya que el diez de agosto del dos mil diecinueve Jeffrey Epstein fue hallado muerto en su celda en la prisión de alta seguridad Manhattan. La oficina del forense confirmó que se trató de un suicidio por ahorcamiento. Se especula que alguno de sus poderosos amigos podría haber pagado para que lo mataran ya que este tenía pruebas contra otros pedófilos.

Lo importante y que no se debe olvidar es que dejó al menos una centena de víctimas.

Además de que esta situación pudo evitarse si hubieran escuchado la primera denuncia que fue formulada por dos hermanas en 1996.

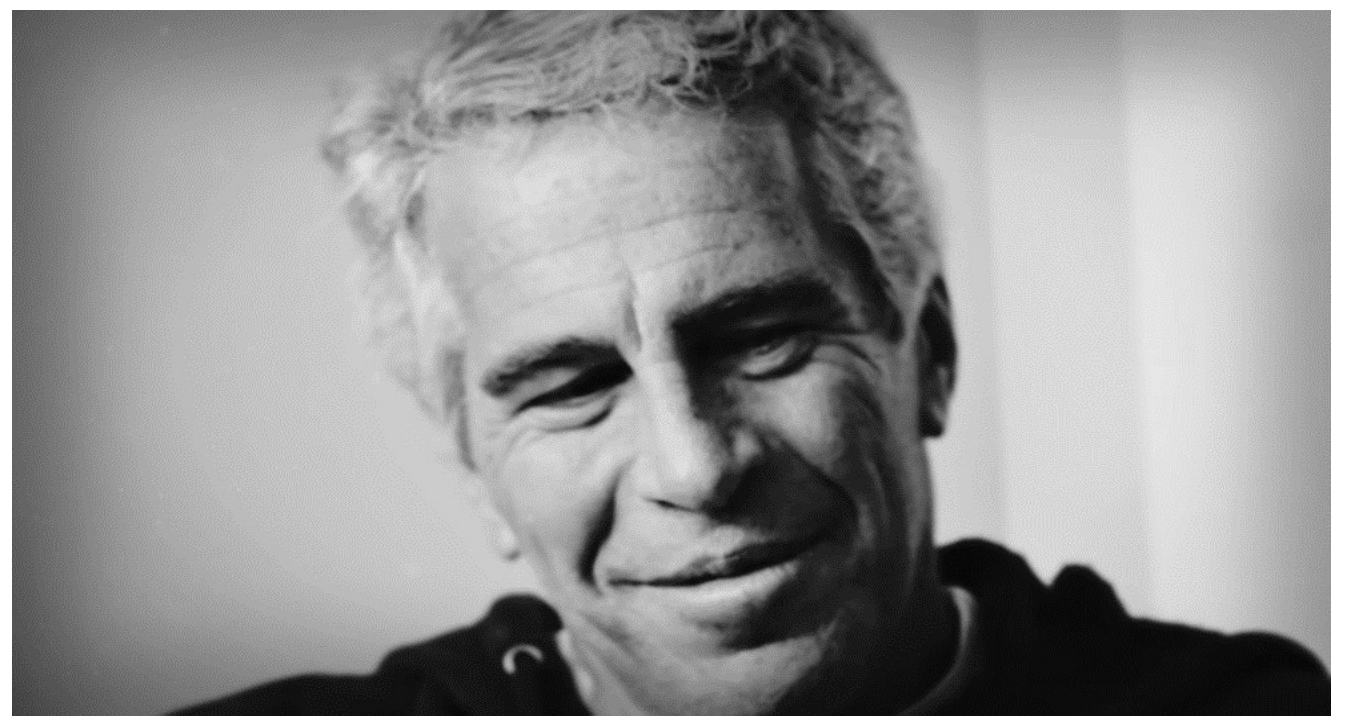




\section{A manera de conclusión}

Ciertamente los crímenes de abuso sexual son más vinculados a mujeres, y con mayor proporción a mujeres muy jóvenes quienes sufren este tipo de abusos de manera repetitiva y en consecuencia frustran su proyecto de vida.

Es necesario entrar en cuenta que es un delito muy concurrente, pero no se puede ver a simple vista debido a que no es prontamente denunciado, ya sea por la minoría de edad de la víctima y eso implica que no sabe que hacer, el miedo de alguna represalia o amenazas, o por la desconfianza que da nuestro sistema de justicia tan teñido de corrupción y malos manejos de quienes deberían velar por el cumplimiento de las leyes en favor de las víctimas.

Como anotamos en el punto de jurisprudencia internacional, Jeffrey Epstein era un multimillonario que fue encarcelado por tejer una red de trata de menores y abuso sexual infantil. El tal Epstein tenía una isla privada donde daba fiestas con distintos personajes (en otras de sus propiedades también abusaban de las menores), y hasta existía un avión llamado "Lolita Express" donde las transportaban, en algunas ocasiones de un país a otro.

Desde luego, también se conoció un audio en el cual el Presidente de los Estados Unidos de Norteamérica Donald Trump hablaba acerca de tener sexo con adolescentes, e incluso leer las declaraciones de supuestas víctimas de la red de Epstein. Una de ellas explica cómo tenía que captar a nuevas menores que querían ser modelos para asistir a estas fiestas (de esta forma se tejía la mentira, las mismas menores con el tiempo debían incluir a otras), y relata como incluye a una niña de 13 años que luego sería abusada sexualmente por Eisptein, y Donald Trump.

Entonces, volviendo a nuestra realidad nacional, lo cierto es que, durante la pandemia y cuarentena para ser precisos, se reportaron casos de abuso sexual infantil dándose de manera diaria, demostrándose que, los agresores se encuentran muchas veces bajo el mismo techo, haciendo más terrible el panorama de la víctima que debería encontrar seguridad en casa, tal vez para ellas no valga nada el lema que ha caracterizado estos últimos meses \#QuédateEnCasa.

\section{REFERENCIAS BIBLIOGRÁFICAS}

- Nieva, J.(2013) La duda en el proceso penal.Buenos Aires, Argentina: Marcial Pons Referencias Electrónicas:

- CÓDIGO PENAL PERUANO. (2018). Código Penal Peruano en línea. Recuperado de: http:// spij.minjus.gob.pe/content/publicaciones_oficiales/img/CODIGOPENAL.pdf

- LEY 28251. (2004). Microsoft Word - Lery 28251.doc. Recuperado de: http://www4.congreso. gob.pe/congresista/2001/edelapuente/leyes/Lery28251.pdf

- DIARIO OFICIAL EL PERUANO. (2018). LEY No 30838 ley que modifica el código penal y el código de ejecución penal para fortalecer la prevención y sanción de los delitos contra la libertad e indemnidad sexuales. Recuperado de: https://busquedas.elperuano.pe/normaslegales/leyque- modifica-el-codigo-penal-y-el-codigo-de-ejecucion-pe-ley-n-30838-1677448-1/

- DIARIO OFICIAL EL PERUANO. (2018). DECRETO LEGISLATIVO No 1410 decreto legislativo que incorpora el delito de acoso, acoso sexual, chantaje sexual y difusión de imágenes, materiales audiovisuales o audios con contenido sexual al código penal, y modifica el procedimiento de sanción del hostigamiento sexual. Recuperado de:https://busquedas. elperuano.pe/normaslegales/decreto-legislativo-que-incorpora-el-delito-de-acoso-acosodecreto-legislativo-n-1410-1690482-3/

- NETFLIX (2020). Jeffrey Epstein, Asquerosamente rico. Recuperado de: https://www.netflix. $\mathrm{com} / \mathrm{search} ? \mathrm{q}=\mathrm{EPSTEIN} \& \mathrm{jbv}=80224905 \& \mathrm{jbp}=0$ \&jbr$=0$ 
- ORGANIZACIÓN MUDIAL DE LA SALUD (2019). Maltrato de menores. Recuperado de: https://www.who.int/topics/child_abuse/es/

- MINISTERIO DE LA MUJER Y POBLACIONES VULNERABLES (2020). Programa Nacional

- contra la Violencia Familiar y Sexual. Recuperado de: https://repositoriopncvfs. pe/?product $=2230$

- FONDO DE POBLACIÓN DE LAS NACIONES UNIDAS (2019). Las Adolecentes Peruanas en Matrimonio o Unión. Recuperado de: https://peru.unfpa.org/sites/default/files/pub-pdf/ estudio- uniones-tempranas-web.pdf

Fecha de recepción: 23 de octubre de 2020

Fecha de aceptación:06 de noviembre de 2020 